at best, a tool for aiding our investigations into the nature of intelligence) might agree that it is unreasonable to expect the success of artificial systems beyond the level of competence.

Weak and strong AI are not unrelated, of course. Proponents of the former have undoubtedly benefited from the public persuasiveness of the latter. But the distinction points to a further shortcoming in the Dreyfuses' case. By concentrating upon proponents of strong AI, the arguments give us little insight into what practitioners of AI do. In this book, the Dreyfuses continue their impressive assault in the titanic struggle between phenomenological philosophy and the rationalist assumptions of AI's public guardians. But we are not told whether or how the assumptions of strong AI touch upon the day-to-day business of devising systems, making programs work, evaluating output and so on.
It is interesting to consider the likely fate of the Dreyfuses' thesis. Their case against AI is the strongest and most eloquent yet published, a protest against conceptions of the human being which have held sway since the beginnings of Western thought, and it suggests that one outcome of the AI debate might be a definitive refutation of the rationalist metaphysic. However, the lack of a fully social conception of the practice of machine intelligence is perhaps reflected in their inattention to one of the key lessons of the history of science: "critical tests" are rarely decisive. Evaluations of "success" and "failure" need only generate further redefinitions of AI, not its abandonment.

Steve Woolgar is a Lecturer in the Department of Human Sciences, Brunel, The University of West London, Uxbridge, Middlesex UB8 $3 P H$, UK. With Bruno Latour he is author of Laboratory Life: The Construction of Scientific Facts, a revised edition of which has recently been published by Princeton University Press.

\section{Wondrous gifts}

\section{Peter Bryant}

Nature's Gambit: Child Prodigies and the Development of Human Potential. By David Henry Feldman with Lynn T. Goldsmith. Basic Books:1986. Pp.259. \$19.95.

EVERY now and then a child turns out to be outstandingly talented in a quite specific way. It is not just that he quickly outstrips all his contemporaries in a particular skill: he also soon becomes a great deal better than most grown-ups at it. Children such as this arouse great interest and wonder. Psychologists in particular have to pay attention to them because at first sight they seem to break most of the rules set out by developmental theories. After all, these theories generally hold that different intellectual skills are connected and that they develop together at roughly the same pace through childhood. How can such theories possibly explain a five-yearold child whose mathematical skills already outstrip those of 95 per cent of the adult population, but who otherwise seems pretty ordinary?

I suspect that this question was the starting point for David Feldman's book, which is a prolonged and detailed study of six different, prodigiously talented American boys and their families, but it is not in the end a question that he answers satisfactorily. Instead he spends most time on another question which is unanswerable, or at any rate cannot be answered from a study of individual child prodigies. His main concern is to find what conditions are needed to produce such children. Feldman's own idea, which is about what he calls the "coincidence process" is neither new nor sophisticated: it is that these children have extraordinary gifts ("proclivities" is Feldman's term) to start with but that their talents only flourish in the right environment. Prodigies need sensitive and devoted parents and an appropriate social environment, according to Feldman, and he is plainly impressed by the lengths to which some of the parents in his little group were prepared to go to support their children. Sacrificing jobs, commuting long distances, confronting awkward teachers, taking the child from one tutor to the next - these seem to be typical demands for a prodigy's parents, and in this group at least they shouldered the burden quite cheerfully. Often the parents' own talents matched their child's: the boy with an extraordinary gift for music had a musician for a father, and the father of the boy who showed early signs of being a talented writer was a writer himself. In these cases the parents spent a great deal of time teaching their own specific skill to their child.

Feldman's argument that all the children in his group were lucky enough to be born into a suitable environment is convincing, but it does not prove his case that such environments are essential for the emergence of a prodigy. The trouble is that his thesis is just as much about children whom he did not study as about the six prodigies with whom he spent so much time. There must, he argues time and again, be children who could have been prodigies, who had the "proclivities", but who found themselves in the wrong environment: the world must be littered with mute, inglorious Miltons or Cromwells guiltless of their country's blood. But Feldman did not study any such prodigy manqué. He does not even demonstrate that they exist, and it is very difficult to see how he could have done so, given his methods.

\section{IMAGE UNAVAILABLE FOR COPYRIGHT REASONS}

Making music - the prodigiously talented Mozart, accompanied by his father and sister.

Feldman's description of the lives of the six boys is interesting and frequently poignant: but it is difficult to see what is new here. After all, we already know a great deal about the childhood of erstwhile prodigies. Mozart's childhood, to take one example, is documented as well as any other part of his life. Sartre, to take another, wrote about his early years in great detail and with considerable distaste. One of the most striking features of these examples and the children studied by Feldman is the surprise and interest that the prodigies excited in the adults around them. The children soon become performers and they do so at the insistence of adults. On occasion, adult astonishment at the child's unexpected talents has some odd results. In my view the most interesting part of Feldman's book is his description of the way in which parents or teachers sometimes resort to irrational explanations for a child's extraordinary talents, because they cannot account for them in any other way. Reincarnation is one solution. The child is thought to be so talented because he is simply a new version of a dead genius.

To read Feldman's sympathetic and sensitive accounts of these six children is to feel the same kind of awe which the young Mozart must have inspired in those who heard him play and improvise so effortlessly. Readers of this book will wonder at the phenomena which Feldman describes, but will remain puzzled about the reasons for them and about the implications for developmental psychology.

Peter Bryant is Watts Professor in the Department of Experimental Psychology, University of Oxford, South Parks Road, Oxford OX1 3UD, $U K$. 